\title{
The influence of advanced age on the morbi-mortality of gastric cancer after curative surgery
}

\author{
Araceli Mayol-Oltra, Roberto Martí-Obiol, Fernando López-Mozos, Gloria Báguena-Requena \\ and Joaquín Ortega-Serrano
}

Esophagus and Gastric Surgery Unit. Service of General and Digestive Surgery. Hospital Clínico Universitario. Valencia, Spain

\begin{abstract}
Introduction: gastric cancer (GC) is the fourth leading cause of cancer death in Spain after lung, colorectal, breast and prostate tumours. Surgery remains the only potentially curative treatment in localized gastric cancer.

Objective: the aim of our study is to evaluate and compare the clinical and surgical aspects, development of postoperative complications and outcomes of patients over 75 years old compared with younger patients in our centre.

Material and methods: comparative retrospective study, from March 2003 to June 2011. We diagnosed 166 cases of GC, 109 (65\%) underwent curative surgery. Two groups were settled: group $\mathrm{M}: \geq 75$ years ( 41 patients) and group $\mathrm{m}:<75$ years (68 patients). We analyzed age, sex, comorbidities, tumour location, clinical stage, perioperative chemotherapy, surgical technique, postoperative complications, recurrence and mortality from cancer.

Results: a more frequent presence of cardiovascular comorbidities and a greater postoperative mortality by medical causes were the only significant differences between both groups. Also, a lower proportion of patients in group $\mathrm{M}$ received preoperative chemotherapy and underwent D1 lymphadenectomy. However, the rate of local and systemic recurrence and overall survival were similar in both groups.

Conclusions: age should not be considered a contraindication for curative surgery on GC. The general condition and comorbidities
\end{abstract} are more important to contraindicate surgical treatment.

Key words: Cancer. Stomach. Elderly. Surgery. Lymphadenectomy. Treatment.

Mayol Oltra A, Martí Obiol R, López Mozos F, Báguena Requena $G$, Ortega Serrano J. The influence of advanced age on the morbi-mortality of gastric cancer after curative surgery. Rev Esp Enferm Dig 2013;105:194-200.

Received: $17-09-2012$

Accepted: $18-02-2013$

Correspondence: Araceli Mayol Oltra. Service of General and Digestive Surgery. Hospital Clínico Universitario. Avda. Blasco Ibáñez 17. 46010 Valencia, Spain

e-mail: aracelimayol@gmail.com

\section{INTRODUCTION}

Gastric cancer (GC) is the fourth cause of death by cancer in both sexes in Spain after lung, colorectal, breast and prostate tumors (1). GC appears with greater frequency after age 60 , and its incidence increases with age $(2,3)$. In the last few decades the proportion of patients older than 80 years with GC has increased from 3 to $17 \%$ in Japan and from 5 to $25 \%$ in the West (4).

Surgery continues to be the only potentially curative treatment for localized gastric cancer $(1,5-8)$. According to Matsushita et al. (9) in the case of advanced GC in patients older than 80 years, the survival rate at 3 years was $36 \%$ in those cases in which surgery is realized and null in those cases that did not receive surgical treatment. These data endorse the use of surgery in elderly patients even though postoperative morbidity after major surgery is higher in these patients. This is perhaps because it has traditionally been considered that there are a greater number of comorbidities associated with them (10).

Recently there is an increase in the incidence of proximal $\mathrm{GC}$ and a decrease in distal ones. Consequently, there appears to be a need to undertake even more aggressive surgery, such as total gastrectomy, in increasingly older patients $(1,2,11,12)$.

The purpose of our study was to evaluate or compare the clinical and surgical aspects, the development of postoperative complications and the evolution in terms of relapse and survival in patients older than 75 years compared with patients younger than 75 years operated on at our center.

\section{MATERIAL AND METHODS}

From March 2003 until June 2011, 166 cases of GC were diagnosed in our hospital. Of these, $109(65 \%)$ were intervened for curative reasons and complete resection (R0), 
and these are the patients analyzed in the present study. The 57 remaining cases were treated palliatively. The data for these patients were gathered prospectively in a database.

Two groups were established according to age: group M: $\geq 75$ years, and group $\mathrm{m}:<75$ years. The selection of the cut off age at 75 years was based on the articles reviewed for study.

The diagnosis was carried out using endoscopy and biopsy, while the extension study was done using thoracicabdominal-pelvic computed tomography (TC) in all cases. If there were doubts about metastatic affection, magnetic resonance imaging (MRI) or positron emission tomography (PET) were used. Beginning in 2007, we used ecoendoscopy to study gastric wall affection in 34 patients.

The controlled use of perioperative chemotherapy began in 2004, and it was indicated for those patients with clinical status $\mathrm{T} \geq 3$ and/or $\mathrm{N}+$. The QT used is based on the Cunningham schema (13) of perioperative QT. The regime administrated was for the most part XELOX ${ }^{\circledR}(1$ dose oxaliplatin $130 \mathrm{mg} / \mathrm{m}^{2}$ followed by capecitabine 2000 $\mathrm{mg} / \mathrm{m}^{2} /$ day for 15 days) in 3 preoperative cycles. Four weeks after finishing chemotherapy, the patients underwent surgery. The patients who presented with a good adaptation to their gastrectomy received 3 cycles of postoperative chemotherapy following the above mentioned schema. In patients $\geq 80$ years, perioperative QT was not administered.

The location of the tumor in the stomach determines the extension of the gastrectomy. For tumors located in the distal third, a partial gastrectomy was realized. In those cases in which it was not possible to obtain a resection margin of 5-7 cm, a total gastrectomy was realized. Except in the cases of precocious stadiums (early), a modified D2 lymphadenectomy was realized according to the tumor location. We carried out splenectomies and lymphadenectomies of the splenic artery in cases of body tumors with clear affection or suspected infiltration of the spleen.

Complications that developed during the first 30 days after the intervention were considered to be postoperative. Postoperative mortality was defined as one which occurred during the first 30 postoperative days or before the patient's discharge. Additionally, data on average length of stay in hospital was gathered for every group.

For the clinical and pathological classification of tumornode-metastases (TNM), the AJCC Cancer Staging Man$u a l, 6^{\text {th }}$ ed. (2002) was used (14).

The follow-up was carried out by means of a clinical and analytical evaluation and a semi-yearly CT during the first two years, annually from the third year. In case of partial gastrectomy, there was an annual endoscopy the first two years. Beginning with the third year, the endoscopy was repeated only in those cases presenting with symptoms. Tumor growth was defined as a local relapse in the anastomosis, the gastrectomy tumor bed, loco-regional adenopathies or remote carcinomatosis and recurrences, such as tumor growth in the liver or any extraperitoneal organ.
The data regarding age, sex, symptoms at diagnosis, presence and type of comorbidities were analyzed retrospectively. Additionally, the tumor location, clinical stadium, administration of perioperative QT, surgical technique utilized, necessity of transfusion during the perioperative period, both appearance of either medical or surgical postoperative complications, as well as their Clavien-Dindo grade (15), relapse and mortality from the neoplasia were evaluated.

The statistical analysis was carried out using the Chisquare test for qualitative variables and the Mann-Whitney $\mathrm{U}$ test for quantitative variables. For the analysis of relapse and survival, the Kaplan-Meier method with the log-rank test was used to analyze the difference between groups. Significance was considered for values of $\mathrm{p}<0.05$.

\section{RESULTS}

We divided the 109 patients curatively intervened for gastric cancer in the study period into two groups: $M \geq 75$ years with 41 patients $(38 \%)$, and $m<75$ years with 68 patients $(62 \%)$.

The data for sex, symptoms, history, tumor location, and use of perioperative QT appear in table I. The only differences found, after having compared both groups, were a greater percentage of patients with heart disease in the older group and a lesser proportion of patients treated with QT within the same group. Tables II and III show the information relative to the surgical treatment used and its results (medical and surgical complications and postoperative mortality). We point out that, upon having analyzed the type of lymphadenectomy realized, a lesser proportion of D2 lymphadenectomy is seen in group $\mathrm{M}$.

Upon analysis of the surgical complications, no significant differences between both groups were seen. A larger number of postoperative exitus is seen in group $\mathrm{M}$, but at the expense of a greater proportion of medical complications. In the older group of patients, two cases of death were a result of medical complications (pneumonia, aspiration pneumonia), another was after duodenal stump leakage, and another after the dehiscence of the esophagus-jejunal anastomosis suture. One occurred in group $\mathrm{m}$ after an esophagus-jejunal suture dehiscence.

The pathological stadiums and follow-up (presence of relapses and mortality from oncological causes) appear in table IV.

The median follow-up was 21 months (2-81 months). During the follow-up period, there were no differences in either the local and/or systemic appearance of relapses or in mortality related to the neoplasia (29\% in group $\mathrm{M} v s$. $22 \%$ in group $\mathrm{m}$ ).

As to global survival (Fig. 1), at 5 years there were no significant differences $(\mathrm{p}=0.12)$, with a median survival time in group $\mathrm{M}$ of $40.6 \pm 5$ months (CI $95 \%$ 29.8-51.4), while in group $m$ it was $48.5 \pm 3$ months (CI $95 \% 42.1$ 54.7). 
Table I. Characteristics of the study groups

\begin{tabular}{|c|c|c|c|}
\hline & Group $M(n=41)$ & Group $M(n=68)$ & $p$ value \\
\hline \multicolumn{4}{|l|}{ Sex } \\
\hline Male & $31(76 \%)$ & $51(75 \%)$ & n.s. \\
\hline Comorbidities & $27(66 \%)$ & $37(54 \%)$ & n.s. \\
\hline Heart disease & $18(44 \%)$ & $3(4 \%)$ & 0.002 \\
\hline HTN & $24(58 \%)$ & $27(40 \%)$ & n.s. \\
\hline Cirrhosis & $2(5 \%)$ & $3(4 \%)$ & n.s. \\
\hline \multicolumn{4}{|l|}{ Tumor location } \\
\hline Proximal & $10(24 \%)$ & $17(25 \%)$ & \multirow[t]{4}{*}{ n.s. } \\
\hline Medial & $13(32 \%)$ & $20(29 \%)$ & \\
\hline Distal & $17(42 \%)$ & $27(40 \%)$ & \\
\hline Stump & $1(2 \%)$ & $4(6 \%)$ & \\
\hline Obstruction & $4(10 \%)$ & $14(21 \%)$ & n.s. \\
\hline Weight loss & $12(30 \%)$ & $23(34 \%)$ & n.s. \\
\hline \multicolumn{4}{|c|}{ TNM stage diagnosis } \\
\hline la & $3(7.3 \%)$ & $8(11.85)$ & \multirow[t]{5}{*}{ n.s. } \\
\hline $\mathrm{lb}$ & $10(24.4 \%)$ & $8(11.8 \%)$ & \\
\hline$\|$ & $14(34.1 \%)$ & $12(17.6 \%)$ & \\
\hline Illa & $12(29.3 \%)$ & $34(50 \%)$ & \\
\hline Illb & $2(4.9 \%)$ & $6(8.8 \%)$ & \\
\hline \multicolumn{4}{|c|}{ Perioperative QT } \\
\hline Yes & $12(30 \%)$ & $41(60 \%)$ & \multirow[t]{2}{*}{0.003} \\
\hline No & $29(70 \%)$ & $27(40 \%)$ & \\
\hline
\end{tabular}

\section{DISCUSSION}

The incidence of the GC increases with age, being diagnosed most often at around 60 years of age $(2,3)$. There has even been an increase in the last few decades in the proportion of 80-year-olds with gastric cancer, rising from 3 to $17 \%$ in Japan and from 5 to $25 \%$ in the West (4).

Some authors have pointed out significant differences between the clinical, surgical and prognostic characteristics in elderly patients with gastric cancer in comparison to those for groups of young patients $(2,11,12)$. After having analyzed the symptoms of presentation with CG, we do not find any differences between both groups. The most frequent symptoms are upper digestive track hemorrhaging or anemic syndrome. Additionally, differences in tumor location have been pointed out $(1,2,11,12)$, something not demonstrated in our study, where the most frequent location in both groups was the gastric distal third.

Traditionally, it has been considered that postoperative morbidity after major surgery is more elevated in elderly patients, perhaps as a result of the greater number of comorbidities in these patients $(10,12,16)$. A concept to also keep in mind is "frailty", which refers to the vulnerability or the physiological reserve of the patient, independent of age, but which still depends partly on the presence of certain comorbidities and how they affect the patient (17). In our study, the presence of comorbidities was significantly greater in the older group, specifically the presence of cardiovascular disease. It is in this group of patients where we must bear in mind both the presence of comorbidities, as well as the physiological reserve (frailty) when making a therapeutic decision $(16,18-20)$.

The most used surgical technique was the partial gastrectomy since our study had a greater proportion of distal gastric cancers. The D1 lymphadenectomy was carried out mainly in the group of $\geq 75$ years, which is statistically significant. This has also been reported in other studies such as the English Lamb et al. study (21) where the elderly patients with risk factors received D1 lymphadenectomies. As to the extent of the lymphadenectomy, there are contradictory data, given that the Japanese studies show a low mortality rate, about $1 \%$ after extensive lymphadenectomies (22-25). In the studies realized in western countries, significantly higher mortality rates appear, between 10-13 $\%(21,26-29)$. This has been related to the differences between Asian and Western populations, where the latter's patients are older, have more concomitant pathologies, a higher thromboembolic risk and tumors that are more proximal which receive more aggressive surgeries. Therefore, many authors defend the position of realizing D1 lym- 
Table II. Surgery employed and its results

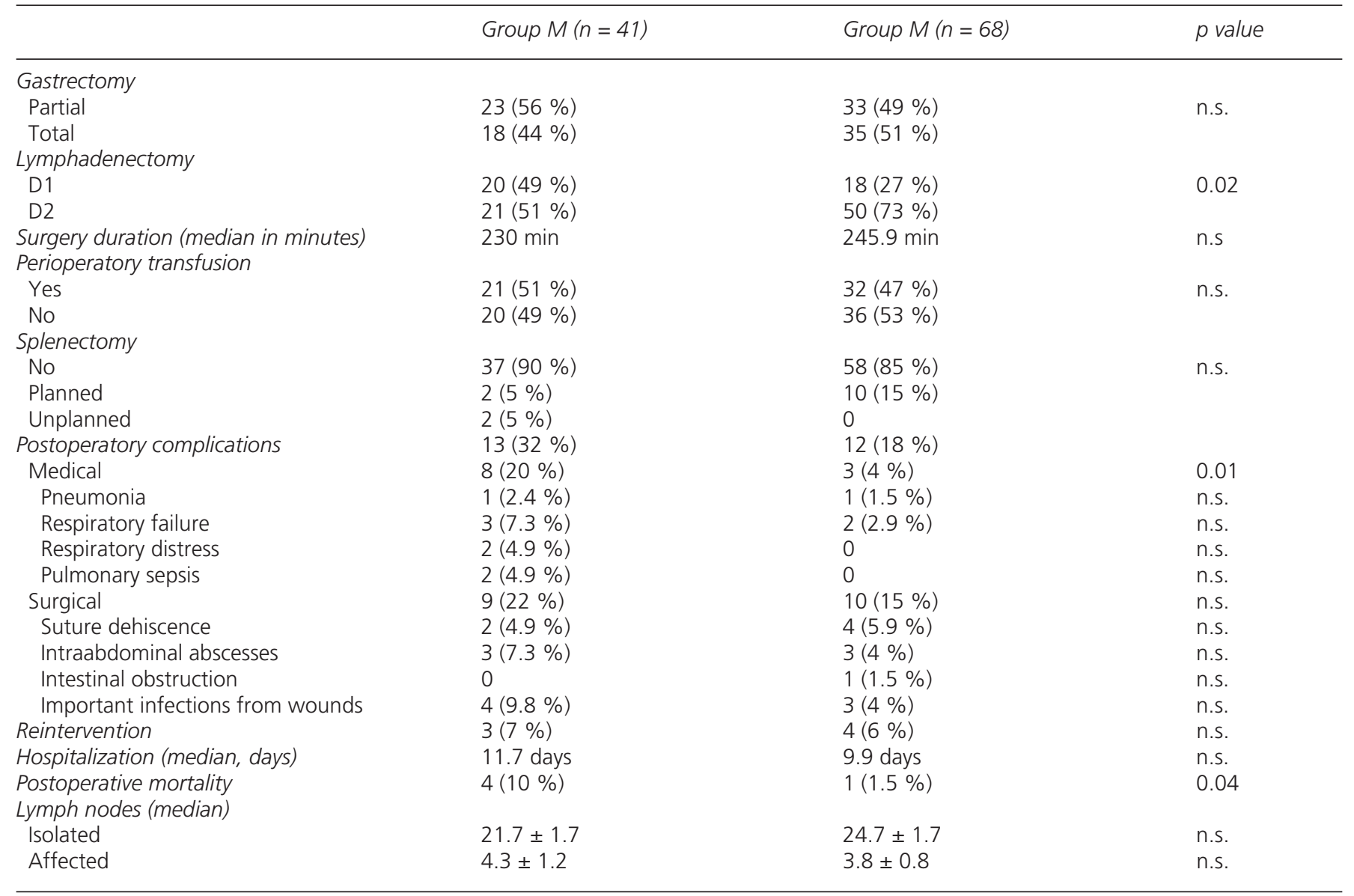

Table III. Postoperative complications using the Clavien-Dindo classification

\begin{tabular}{llll}
\hline Clavien-Dindo Grades & Group $M(n=41)$ & Group $M(n=68)$ & $p$ value \\
\hline Grade 1 & $30(73.1 \%)$ & $20(29.4 \%)$ & 0.03 \\
Grade 2 & $22(53.7 \%)$ & $34(50 \%)$ & n.s. \\
Grade 3 & $9(22 \%)$ & $14(20.6 \%)$ & n.s. \\
Grade 4 & $6(14.6 \%)$ & $4(5.9 \%)$ & 0.04 \\
Grade 5 & $4(14.6 \%)$ & $1(1.5 \%)$ & 0.04 \\
\hline
\end{tabular}

phadenectomies in aged patients with concomitant illnesses $(4,18,30,31)$, although some specialized European centers refer to a 2-5\% mortality rate after radical gastric surgery and D2 lymphadenectomies (32,33). In the study developed by the British Cooperative Group that compared the D2 lymphadenectomy with the D1, the survival rates at five years were similar (33 vs. $31 \%$, respectively) a greater morbimortality being seen in the group which received a D2 lymphadenectomy $(34,35)$. Similar results were published by other groups (34,36-39). Standing out among them all is the study developed by the Dutch Gastric Cancer Group, which compared the D2 lymphadenectomy with the D1, it showed a greater morbidity (43 vs. $25 \%$ ) and postoperative mortality (10 vs. $4 \%$ ) in the D2 lymphadenectomy group, without appreciative differences in the accumulative survival rate at five years $(35$ vs. $30 \%)(34,37)$. Nevertheless, in the analysis of the follow-up of this study at 15 years, there were lower local recurrence and mortality rates for the illness for the group with D2 lymphadenectomy compared with those for D1, with the most prominent difference being observed in those patients with N2 disease (19 vs. $0 \%)(34,39)$. The factors related to a greater morbidity in 
Table IV. Anatomopathological stadiums and their evolution

\begin{tabular}{|c|c|c|c|}
\hline & Group $M(n=41)$ & Group $M(n=68)$ & $p$ value \\
\hline \multicolumn{4}{|l|}{ A-P stadiums } \\
\hline la & $7(17 \%)$ & $14(21 \%)$ & \multirow[t]{4}{*}{ n.s. } \\
\hline$\|$ & $9(22 \%)$ & $12(18 \%)$ & \\
\hline IIIa & $7(17 \%)$ & $18(26 \%)$ & \\
\hline IIlb & $9(22 \%)$ & $14(21 \%)$ & \\
\hline Systemic & 0 & $7(10 \%)$ & \multirow{2}{*}{ n.s 0.1} \\
\hline Both & $1(2 \%)$ & $1(2 \%)$ & \\
\hline Mortality by neoplasia & $12(29 \%)$ & $15(22 \%)$ & n.s. 0.4 \\
\hline
\end{tabular}

the D2 group were the following: aged over 65 years, the male, the type of gastrectomy, and also the realization of a splenectomy and/or pancreatectomy. In our study, there was a bias present when analyzing the postoperative mortality since we carried out more D1 lymphadenectomies in the elder group, which might be associated with a lower postoperative mortality than if we had done D2 lymphadenectomies in this group $(34,40)$.

Regarding postoperative complications, there was a greater rate of medical complications in the elder group as opposed to that for those younger than 75 years. This difference was statistically significant, as was the case in the Bittner et al. study (12). Nevertheless, other studies $(4,22)$ have not demonstrated a greater rate of medical or surgical

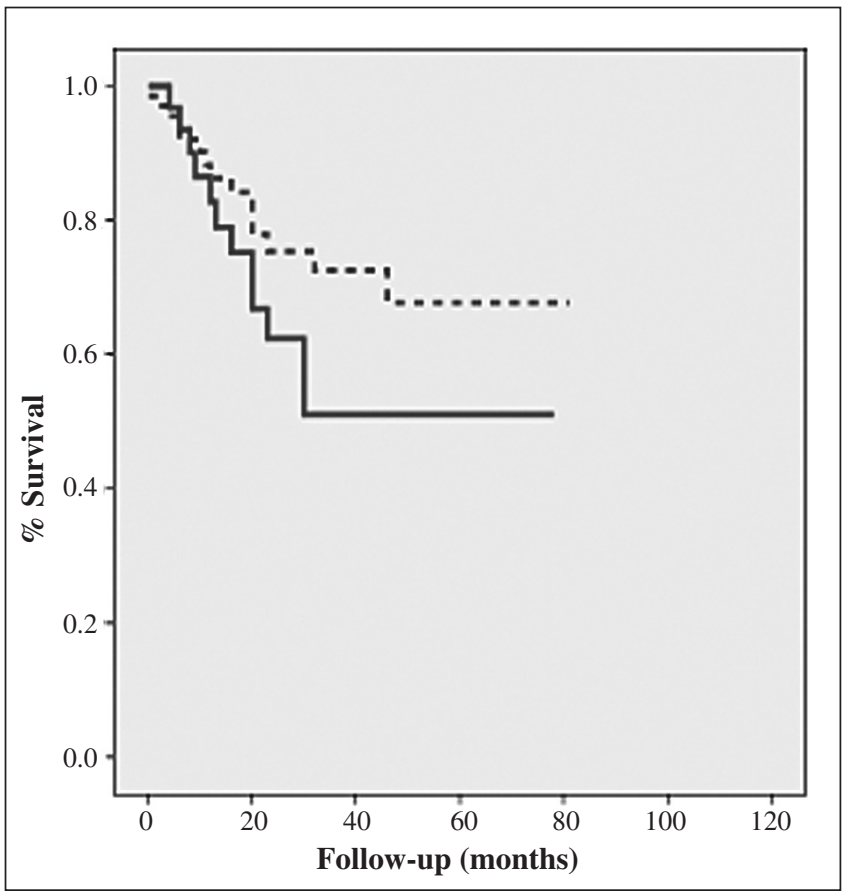

Fig. 1. Comparison of global survival between groups (log rank $p=0.1)$ (discontinuous line: younger than 75; continuous line: older than 75). complications than that for the elders of our study. In our study, there were no differences in either the surgical complications or the need for reinterventions, although we demonstrate differences between both age groups after analyzing the postoperative mortality, larger in the elder group as a result of medical complications. This can be explained as they were the patients with the greater proportion of comorbidities. This agrees with the Butte et al. data (2) which explains the increase in mortality as being the result of the presence of risk factors in patients.

We did not find the differences between the tumor stadiums of the patients of both groups as did other studies $(1,12)$. Although other authors did relate the elder patients to more advanced tumor stadiums and therefore to a worse prognosis $(22,41)$.

During the follow-up, the rates of relapse and of survival were similar in both age groups, as shown in other studies, depending principally on the tumor stadium $(4,16,18,42)$. In the analyses with differences in the survival rate between younger and older patients, the tumors of the latter patients were more advanced than were those of the younger patients $(4,16,22,31)$.

Consequently, we can conclude by saying that when it is possible to treat surgically and with curative intention, the disease-free survival and global rates are comparable in older and younger patients. Therefore, age should not be considered a contraindication for realizing curative surgery for GC. Nevertheless, it should be the general condition, the physiological reserve or vulnerability of the patient ("frailty") and the comorbidities that contradict surgical intervention.

\section{REFERENCES}

1. García Marcilla JA, Parrilla P, Piñero A. Cáncer Gástrico: epidemiología y factores de riesgo. En: Parrilla Paricio P, Martínez de Haro L, Ortiz Escandell A (eds.). Guía Clínica de Cirugía Esofagogástrica AEC. Madrid: Arán Ediciones; 2001. p. 437-51.

2. Butte JM, Duarte I, Crovari F, Guzmán S, Llanos O. Cáncer gástrico en pacientes de 75 años. Tratamiento quirúrgico y supervivencia a largo plazo. Cir Esp 2007;82:341-5.

3. Hohenberger P. Gastric Cancer. Lancet 2003;362:305-15. 
4. Coniglio A, Tiberio GAM, Busti M, Gaverino G, Baiocchi L, Piardi $\mathrm{T}$, et al. Surgical treatment for gastric carcinoma in the elderly. J Surg Oncol 2004;88:201-5.

5. Katai H, Sasako M, Sano T, Maruyama K. The outcome of surgical treatment for gastric carcinoma in the elderly. Jpn J Clin Oncol 1998;28:112-5.

6. Wanebo HJ, Kennedy BJ, Chmiel J, Steele G, Winchester D, Osteen R. Cancer of the stomach: A patient care study by the American College of Surgeons. Ann Surg 1993;218:583-92.

7. Damhuis RA, Tilanus HW. The influence of age on resection rates and postoperative mortality in 2773 patients with gastric cancer. Eur J Cancer 1995;31A:928-31.

8. Kranenbarg K, Van de Velde JH. Gastric cancer in the elderly. Eur J Surg Oncol 1998;24:384-90.

9. Matsushita I, Hanai H, Kajimura M, Tamakoshi K, Nakajima T, Matsubayashi Y, et al. Should gastric cancer patients more than 80 years of age undergo surgery? Comparison with patients not treated surgically concerning prognosis and quality of life. J Clin Gastroenterol 2002; 35:29-34.

10. Kitamura K, Yamaguchi T, Taniguchi H, Hagiwara A, Yamane T, Sawai K, et al. Clinicopathological characteristics of gastric cancer in the elderly. Br J Cancer 1996;73:798-802.

11. Gong DJ, Miao CF, Bao Q, Jiang M, Zhang LF, Tong XT, et al. Risk factors for operative morbidity and mortality in gastric patients undergoing total gastrectomy. World J Gastroenterol 2008;14:6560-3.

12. Bittner R, Butters M, Ulrich M, Uppenbrink S, Beger HG. Total gastrectomy. Updated operative mortality and long-term survival with particular reference to patients older than 70 years of age. Ann Surg 1996;224:37-42.

13. Cunningham D, Allum WH, Stenning SP, Thompson JN, Van de Velde CJ, Nicolson M, et al. Perioperative chemotherapy versus surgery alone for resectable gastroesophageal cancer. N Engl J Med 2006;355:11-20.

14. AJCC. AJCC Cancer Staging Manual. 6th ed. New York, NY: Springer; 2002. p. 99-106.

15. Dindo D, Demartines N, Clavien PA. Classification of surgical complications, A new proposal with evaluation in a cohort of 6,336 patients and results of a survey. Ann Surg 2004; 244:931-7.

16. Eguchi T, Fujii M, Takayama T. Mortality for gastric cancer in elderly patients. J Surg Oncol 2003;84:132-6.

17. Bergman H, Ferrucci L, Guralnik J, Hogan DB, Hummel S, Karunananthan $\mathrm{S}$, et al. An emerging research and clinical paradigm-Issues and controversies. J Gerontol A Biol Sci Med Sci 2007;62:731-7.

18. Eguchi T, Takahashi Y, Ikarashi M, Kasahara M, Fujii M. Is extended lymph node dissection necessary for gastric cancer in elderly patients? Eur J Surg 2000;166:949-53.

19. Teixeira CR, Haruma K, Teshima H, Yoshihara M, Sunii K, Kajiyama G. Endoscopic therapy for gastric cancer in patients more than 80years-old. Am J Gastroenterol 1991;86:725-8.

20. Damhuis RA, Tilanus HW. The influence of age on resection rates and postoperative mortality in 2,773 patients with gastric cancer. Eur J Cancer 1995;31A:928-31.

21. Lamb P, Sivasshanmugan T, White M, Irving M, Wayman J, Raimes S. Gastric Cancer surgery - A balance of risk radicality. Ann R Coll Surg Engl 2008;90:235-42.

22. Saito H, Osaki T, Murakami D, Sakamoto T, Kanaji S, Tatebe S, et al. Effect of age on prognosis in patients with gastric cancer. ANZ J Surg 2006;76:458-61.

23. Maehara Y, Oshiro T, Oiwa H, Oda S, Baba H, Akazawa K, et al. Gastric carcinoma in patients over 70 years of age. Br J Surg 1995;82:102-5.

24. Takeda J, Tanaka T, Koufuji K, Kodama I, Tsuji Y, Kakegawa T. Gastric cancer surgery in patients aged at least 80 years old. Hepatogastroenterology 1994;41:516-20.
25. Moriguchi S, Kamakura T, Odaka T. Clinical features of the differentiated and undifferentiated types of advanced gastric carcinoma: Univariate and multivariate analyses. J Surg Oncol 1991;48:202-6.

26. Cuschieri A, Fayers P, Fielding J, Craven J, Bancewicz J, Joypaul V, et al. Postoperative morbidity and mortality after D1 and D2 resections for gastric cancer: Preliminary results of the MRC randomised controlled surgical trial. The Surgical Co-operative Group. Lancet 1996; 347:995-9.

27. Bonenkamp JJ, Songun A, Hermans J, Sasako M, Welvaart K, Plukker JTM, et al. Randomised comparison of morbidity after D1 and D2 dissection for gastric cancer in 996 Dutch patients. Lancet 1995;345:7458 .

28. McCulloch P, Ward J, Tekkis PP. Mortality and morbidity in gastrooesophageal cancer surgery: Initial results of ASCOT multicentre prospective cohort study. BMJ 2003;327:1192-7.

29. Pye JK, Crumplin MK, Charles J, Kerwat R, Foster ME, Biffin A. Oneyear survey of carcinoma of the oesophagus and stomach in Wales. $\mathrm{Br}$ J Surg 2001;88:278-85.

30. Yamamoto A, Kouno H, Funakoshi M, et al. Comparison of surgical therapy and nonsurgical therapy for the prognosis of gastric cancer in the elderly. J Jpn Soc Clin Surg. 1998;59:1984-8.

31. Sasako M. Risk factors for surgical treatment in the Dutch Gastric Cancer Trial. Br J Surg 1997;84:1567-71.

32. Roukos DH, Lorenz M, Encke A. Evidence of survival benefit of extended (D2) lymphadenectomy in western patients with gastric cancer based on a new concept: A prospective long-term follow-up study. Surgery 1998;123:573-8.

33. Roviello F, Marrelli D, Morgagni P, de Manzoni G, Di Leo A, Vindigni C, et al. Survival benefit of extended D2 lymphadenectomy in gastric cancer with involvement of second level lymph nodes: A longitudinal multicentre study. Ann Surg Oncol 2002;9:894-900.

34. Viudez-Berral A, Miranda-Murua C, Arias-de-la-Vega F, HernándezGarcía I, Artajona-Rosino A, Díaz-de-Liaño Á, Vera-García R, et al. Current management of gastric cancer. Rev Esp Enferm Dig 2012; 104:134-41.

35. Cuschieri A, Weeden S, Fielding J, Bancewicz J, Craven J, Joypaul V, et al. Patient survival after D1 and D2 resections for gastric cancer: Long-term results of the MRC randomized surgical trial. Surgical Cooperative Group. Br J Cancer 1999;79:1522-30.

36. Dent DM, Madden MV, Price SK. Randomized comparison of R1 and R2 gastrectomy for gastric carcinoma. Br J Surg 1988;75:110-2.

37. Hartgrink HH, van de Velde CJ, Putter H, Bonenkamp JJ, Klein Kranenbarg E, Songun I, et al. Extended lymph node dissection for gastric cancer: Who may benefit? Final results of the randomized Dutch gastric cancer group trial. J Clin Oncol 2004;22:2069-77.

38. Robertson CS, Chung SC, Woods SD, Griffin SM, Raimes SA, Lau JT, et al. A prospective randomized trial comparing R1 subtotal gastrectomy with R3 total gastrectomy for antral cancer. Ann Surg 1994;220:176-82.

39. Degiuli M, Sasako M, Calgaro M, Garino M, Rebecchi F, Mineccia M, et al. Morbidity and mortality after D1 and D2 gastrectomy for cancer: Interim analysis of the Italian Gastric Cancer Study Group (IGCSG) randomized surgical trial. Eur J Surg Oncol 2004;30:303-8.

40. Songun I, Putter H, Kranenbarg EM, Sasako M, van de Velde CJ. Surgical treatment of gastric cancer: 15 years follow-up results of the randomized nationwide Dutch D1D2 trial. Lancet Oncol 2010;11:439-49.

41. Kubota H, Cotoh T, Dhar D. Gastric resection in the aged ( $\geq 80$ years) with gastric carcinoma: Multivariate analysis of prognostic factors. Aust N Z J Surg 2000;70:254-7.

42. Katai H, Sasako M, Sano T, Fukagawa T. The outcome of surgical treatment for gastric carcinoma in the elderly. Jpn J Clin Oncol 1998;28:112-5. 